\title{
Sinn Warum verzichten wir auf das Paradies?
}

R eligionen verschaffen den Gläubigen den Vorteil, über Riesseits und Jenseits mehr zu wissen, als Erfahrung und Verstand hergeben. Solange Kult oder Theologie die Existenz Gottes gewährleisten und auf eine Begegnung mit ihm nach dem Tode hoffen lassen, ist die Frage nach dem Sinn des Lebens beantwortet, ehe sie gestellt wird. Es ist eine der größten Überraschungen in der Geschichte der Menschheit, dass sich zuerst einzelne Freigeister der frühen Neuzeit, dann aber auch die Massen jener Gewissheit entschlagen und auf Aussagen über den Zweck des Kosmos und den Sinn des Lebens verzichten. Nicht nur die Heroen der Aufklärung, auch ihre schlichteren Nachfolger - dazu zählt inzwischen die Hälfte der deutschen Bevölkerung - kommen gut ohne Gott, Himmel, Unsterblichkeit, sogar ohne esoterischen Ersatz aus. Wie ist diese außerordentliche Leistung der großen Zahl, die sich einer intellektuellen Revolution angeschlossen hat, zu erklären? Haben sie entdeckt, dass Geborgenheit durch einen verbrieften Sinn mit der Einschränkung der persönlichen Freiheit erkauft werden muss? Ist das moderne Leben so glücklich und abwechslungsreich geworden, dass die Aussicht auf paradiesische Langeweile erschreckt? Fällt das Eingeständnis, »keine Ahnung «von einer anderen Welt zu haben, so leicht, weil es den Stolz bekundet, am Fortschritt menschlicher Erkenntnis teilzuhaben? 